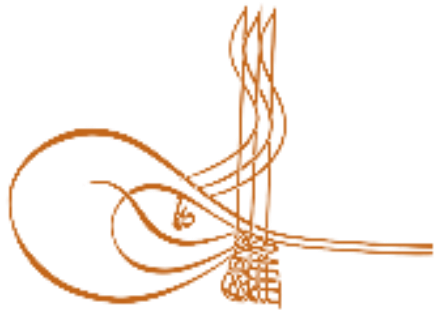

www.turkishstudies.net/social
Turkish Studies - Social Sciences

eISSN: $2667-5617$

Research Article / Araştırma Makalesi

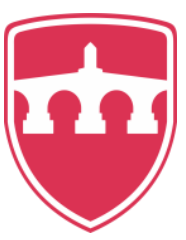

INTERNATIONAL

BALKAN

UNIVERSITY

Sponsored by IBU

\title{
İnanç Turizmi Alanında Yayımlanan Yüksek Lisans ve Doktora Tezlerinin Bibliyometrik Analizi (1998-2019)
}

\author{
Bibliyometric Analysis of Postgraduate and Phd Dissertations in the Field of Faith Tourism in \\ Turkey (1998-2019)
}

\author{
Ertan Özçoban*
}

\begin{abstract}
Faith tourism increases its own market share in the global tourism mobility and Turkey. Turkey is also one of the most attractive destinations that frequently visited by its religiously oriented position. Turkey, which hosts different civilizations and is the center of cultural and religious interactions, has established itself in international tourism mobility through existing or potential faith tourism destinations. Spiritual spaces, experienced by visitors from different geographies each year, constitute a rich source of data for the world of science. The interest in religious and cultural sites where historical and cultural heritage integrates with the roots of faith has been and continues to be the subject of scientific research within the scope of special interest tourism. Although there are bibliometric studies published in the field of tourism, no bibliometric studies on faith tourism have been found. From this point of view, in this study, it is aimed to examine the postgraduate and Phd dissertations with the title 'faith tourism' between 1998 and 2019 with specific criteria. For this purpose, 47 dissertations that have open access in Council of Higher Education dissertation center has been examined and analyzed. Dissertations has been examined under the headings of 'genre', 'year', 'university', 'institute', 'department', 'title,' 'number of pages', 'regional distribution' and 'research method'. The results have been interpreted by statistical data and it was aimed to contribute to the subsequent scientific studies.
\end{abstract}

Structured Abstract: In this study, it is aimed to examine the postgraduate and Phd dissertations with the title 'faith tourism' between 1998 and 2019 with specific criteria. For this purpose, 47 dissertations that have open access in Council of Higher Education dissertation center in Turkey has been examined and analyzed. Dissertations has been examined under the headings of 'genre', 'year', 'university', 'institute', 'department', 'title,' 'number of pages', 'regional distribution' and 'research method'. The results have been interpreted by statistical data so as to contribute to following scientific studies.

Faith tourism has been increasing its own market share in the global tourism mobility and Turkey day by day. Furthermore; among the destinations favored for religious circumstances, Turkey is recognized for being preferred as one of the most regilious oriented destinations. Turkey, which is a cradle of different civilizations and being the center of cultural and religious interactions, has remarked itself in international tourism mobility through existing or potential faith tourism destinations. Spiritual divine places, experienced

\footnotetext{
"Misafir Öğretim Görevlisi, Dr., Ankara Hacı Bayram Veli Üniversitesi, Turizm Fakültesi, Rekreasyon Yönetimi Bölümü Guest Lecturer, Phd., Ankara Hacı Bayram Veli University, Faculty of Tourism, Recreation Management

*Kültür ve Turizm Bakanlı̆̆

ORCID 0000-0001-8282-1731

ertan.ozcoban@hbv.edu.tr

Cite as/ Atıf: Özçoban, E. (2020). İnanç turizmi alanında yayımlanan yüksek lisans ve doktora tezlerinin bibliyometrik analizi (1998-2019), Turkish Studies - Social, 15(3), 1363-1375. https://dx.doi.org/10.29228/TurkishStudies.41530

Received/Geliş: 30 January/Ocak 2020

Accepted/Kabul: 25 April/Nisan 2020

Checked by plagiarism software

Copyright $($ INTAC LTD, Turkey 
by visitors from different countries each year, constitute a rich source of data for the world of science. The interest in religious and cultural sites where historical and cultural heritage integrates with the roots of faith has been and continues to be the subject of scientific research within the scope of special interest tourism. Although there are some bibliometric studies published in the field of tourism, no bibliometric studies on faith tourism have been ever found.

Although it is frequently used in the field with religious tourism, there is a difference between the two concepts. The main difference is that the scope of faith is broader. (Doğaner, 2013: 291) The scientific use of conceptual expressions in research essays on belief systems with historical depth, dating from the emergence of man to the present day, is important. For these reasons, the study is limited to postgraduate and Phd dissertations which has been written under the title of 'faith tourism'.

Qualitative research method (type scan) has been used in the research. The parameters used in the study are; the type of dissertations, the year they was prepared, the university where the dissertations was prepared, the institute where the dissertations was written, the distribution of the dissertations according to the departments, the titles of the consultants in the dissertations, the number of pages of dissertations, the distribution of the universities in which dissertations are written by region and the research methods used in dissertations. It is aimed to examine the 47 postgraduate dissertations in the Higher Education Council Dissertation Center between the years of 1998 and 2019 with the expression "faith tourism" under bibliometry method. In line with the purpose of the study, the research questions that guide the parameters applied to the dissertations are as follows:

a) What are the types of the distribution of dissertations prepared according to the title of faith tourism?

b) How is the year index of the the dissertations as per year that appeared/written?

c) What is the gradation of the university names that dissertations have been prepared? tourism?

d) What is the sorting of the graduate institutes of the dissertations regarding the topic of the faith

e) What is the distribution of dissertations according to their departments?

f) What is the distribution of the consultants of dissertations in dissertations according to their titles?

g) How many numbers of page do that dissertations consisted?

h) Which research methodology is used in the dissertations?

i) What are the frequencies differentiate into the distribution of dissertations prepared in the title of faith tourism by region?

The screening of the dissertation in the title of faith tourism was carried out by entering the keyword 'faith tourism' in the scanning term section of the Higher Education Council Dissertation Center database and marking the area part to be searched as 'dissertation name', permission status 'all' and dissertation type 'all'. A total of 47 postgraduate and doctoral dissertation were reached as a result of the screening conducted on 09.12.2019 (tez.yok.gov.tr). Higher Education Council Dissertation Center central records, the first dissertation with the expression of faith tourism in the title was published in 1998 in Gazi University. In this respect, chronology has been kept in the foreground and the first dissertation on the field and the years in which the last dissertation has been published are based on the bibliometric analysis of the dissertation written in the field of faith tourism.

According to the findings, $96 \%$ of the published dissertation were postgraduate and $4 \%$ were Phd dissertation. In the field of faith tourism, which the topics that can be examined scientifically are dense, it has been observed that there are few postgraduate dissertation written in Turkey. In addition, the number of Phd. dissertation written in this field is only 2. According to the distribution of dissertations written in the title of faith tourism by year, it has been observed that there were no postgraduate dissertations between 1999-2004 and 2006-2008. It has been determined that the studies in this field have gained momentum since 2008 and the density is in psotrgraduate dissertations.

The number of universities where dissertation related to faith tourism has been written at constitutes that $13.30 \%$ of the total number of universities in Turkey (203 universities) at 2019. The dissertations, which 
are seen to have been prepared especially in universities with graduate curriculum for this field, are written in all regions except the Eastern Anatolia region when the distribution is examined according to the regions in Turkey. It was determined that the dissertation written in universities in the Aegean, central Anatolia and Marmara regions constituted $72.33 \%$ of the total number of dissertation written in the field of faith tourism. In the Eastern Anatolia region, where places of worship and religious places of historical value are frequently seen, a postgraduate study in the field of faith tourism has not been seen, especially in this region, wealth is not adequately studied in the scientific field.

43 of the 47 dissertation written in the field of faith has been prepared in the social sciences institutes of universities. The number of dissertation prepared in the Institutes of Educational Sciences and Natural Sciences is small. It is natural that the dissertations on faith tourism, which allows the examination of two different areas such as Tourism and Religious Sciences, in the integrity of interdisciplinary work, should be prepared in the Institutes of Social Sciences. 51.6\% of the dissertation has been written in the Department of Tourism Management, $14.89 \%$ of which have been prepared in the fields of business administration and $8.51 \%$ in Tourism Management and Hotel Management. It has been observed that the studies were carried out largely $(40.42 \%)$ under the guidance of professor-appointed academicians. $70.21 \%$ of graduate studies have a 100-199 page number and the rate of dissertation under 100 pages remains at $12.76 \%$.

Keywords: Faith Tourism, Alternative Tourism, Sustainable Tourism, Bibliyometrics

Öz: İnanç turizmi; alternatif turizm ve buna bağlı turistik ürün çeşitliliğinin önem kazandığı küresel turizm hareketliliği içindeki pazar payını artırırken, sahip olduğu dînî eksenli destinasyonlar yönüyle sıkça ziyaret edilen çekim merkezlerinden biri de Türkiye olmaktadır. Tarihsel süreçte, farklı medeniyetlere ev sahipliği yapan, kültürel ve dini etkileşimlerin merkezi konumunda olan Türkiye'nin zengin birikimi, mevcut ya da potansiyel inanç turizmi destinasyonları kanalıyla, uluslararası turizm hareketliliği içinde kendine yer edinmiştir. Her yıl farklı coğrafyalardan gelen ziyaretçilerin deneyimlediği manevi mekânlar, bilim dünyası için zengin bir veri kaynağı oluşturmaktadır. Tarihi ve kültürel mirasın, inanç kökleriyle bütünleştiği dini ve kültürel mekânlara gösterilen ilgi, özel ilgi turizmi kapsamındaki bilimsel araştırmalara konu olmuş ve olmaya devam etmektedir. Yerli alanyazında, turizm alanında yayımlanmış bibliyometrik çalışmalar bulunmakla birlikte, salt inanç turizmini konu alan ve bu başlık üzerine yazılmış tezlere dönük, herhangi bir bibliyometrik çalışmaya rastlanılmamıştır. Buradan hareketle, bu çalışmada, 1998-2019 yılları arasında, başlığında 'inanç turizmi' ifadesi bulunan yüksek lisans ve doktora tezlerinin, belirli kriterlerle incelenmesi amaçlanmıştır. Bu amaç doğrultusunda, YÖK tez merkezinde erişime açık 47 tez incelenerek analiz edilmiştir. Tezler, 'tür', 'yıl', 'üniversite', 'enstitü', 'anabilim dalı', 'ünvan, 'sayfa sayısı, 'bölgelere göre dağılım' ve 'araştırma yöntemi' başlıkları altında incelenmiştir. Elde edilen sonuçlar, istatistiki verilerle tablolaştırılarak yorumlanmış ve bundan sonraki bilimsel çalışmalar için katkı sağlaması hedeflenmiştir.

Anahtar Kelimeler: İnanç Turizmi, Alternatif Turizm, Sürdürülebilir Turizm, Bibliyometri

\section{Giriş}

Günümüzde, turist taleplerindeki değişim, alternatif turizm kapsamında değerlendirilebilecek destinasyonlara dönük seyahat planlamalarını şekillendirmekte ve yeni tur güzergahlarına göre dönüşen turistik ürün ve hizmetler, pazardaki alanını genişletmektedir (Sünnetçioğlu, vd., 2017: 346). Bu alanlardan biri de inanç turizmidir. Tarihi, kültürel mirasa sahip, farklı dinlerin doğduğu ya da yayıldığı coğrafyalar, inanç turizmi açısından rağbet görürken; turizm potansiyeline sahip, dini sembol, simge ya da mekânları bünyesinde barındıran ülke ve kentlerin de, bu turizm çeşidi yoluyla farkındalık yaratma çabaları gün geçtikçe devam etmektedir. İnsanlığın en eski tapınaklarından, çok çeşitli dinlerin inanç koridoruna kadar ev sahipliği yapan Türkiye, dünya inanç turizmi hareketliliği içinde önemli bir konuma sahiptir. Dünya Turizm Örgütü raporuna göre, her yıl 300 milyon uluslararası ziyaretçinin dini mekânları ziyaret etmekte ve dînî amaçla seyahat edenler, dünyadaki toplam turist sayısının yaklaşı $\% 25$ 'ini oluşturmaktadır ( https://cf.cdn.unwto.org). Bu kapsamda değerlendirildiğinde, Türkiye'nin inanç destinasyonlarına 
yapılan seyahatlerden elde edilen verilerin akademik araştırmalara hangi düzeyde yansıdığı, bu çalışmanın temel problematiğini oluşturmaktadır.

Dînî yerler, mekânlar ve kutsal kentlerin ziyareti ile dînî toplantı ve törenlerin deneyimlenmesinden oluşan inanç turizmi, merak ve gözlem dürtüsünün baskın olduğu turist gruplarının yüksek oranda tercih ettiği bir turizm türüdür ( Kaynak ve Sezgin, 2008: 351-354). Kültürel çekiciliklerin ve kutsal dinamiklerin, turistler için hazırlanan hizmet sunumunun en önemli bileşeni olduğu inanç turizminde, seyahat içeriğinin ve planlamasının, özüne uygun ve bağlamından koparılmadan yürütülmesi hem ulusal hem de uluslararası alanda Türkiye'nin tanıtımı ve bu alandaki farkındalığı açısından önem arz etmektedir.

Alanyazında, inanç turizmi, dînî turizm ile birlikte sıkça kullanılmasına rağmen iki kavram arasında farklılık bulunmaktadır. Temel farklılık, inancın kapsamının daha geniş olmasıdır. ( Doğaner, 2013: 291) İnsanın ortaya çıkışından günümüze kadar uzanan, tarihi derinliğe sahip, inanç sistemleri üzerine yapılacak araştırmalardaki kavramsal ifadelerin bilimsel literatüre uygun kullanımı önem arz etmektedir. Bu açıdan değerlendirildiğinde, çalışma, 'inanç turizmi' başlığ altında yazılan yüksek lisans ve doktora tezleriyle sınırlandırılmıştır.

\section{Turizm Literatüründe Bibliyometrik Çalışmalar}

Turizm ile ilgili alanyazında pek çok bibliyometrik çalışmanın gerçekleştirildiği görülmektedir (Temizkan vd.,2015; Çiçek ve Kozak, 2012; Özel ve Kozak, 2012; Zencir ve Kozak, 2012; Şahin ve Acun, 2015; Demirbulat ve Dinç, 2017; Karagöz ve Kozak, 2014; Y1lmaz, 2017; Bozok vd., 2017; Arslan ve Emeksiz,2016; Sökmen ve Özkanl1, 2018; Tayfun vd., 2018; Aydın, 2017; Altaş, 2017; Tayfun vd.,2016; Ayaz ve Türkmen, 2018; Atınç, vd.,2018; Boyraz ve Sandıkçı, 2018; Aydın ve Aksöz,2019; Yılmaz, vd., 2017; Tayara ve Özel, 2019; Düşmezkalender,2019; Çolakoğlu vd.,2019). Turizm alanında yazılan tezlerin, sunulan bildirilerin, makalelerin ya da bu alanda yayın hayatını sürdüren dergilerin konu alındığı çalışmalarda elde edilen istatistiki verilerin yorumlanması, bibliyometrik çalışmaların temelini oluşturmaktadır. Konu ile ilgili literatür incelendiğinde en kapsamlı araştırmanın Kozak (1996) tarafından yapıldığı tespit edilmiştir. Çalışmada, 1952- 1995 yılları arasında yayımlanmış lisansüstü tezler ile doçentlik ve profesörlük çalışmaları bibliyometri yöntemiyle incelenmiş ve kitaplaştırılmıştır.

Turizm alanında yayımlanmış yüksek lisans ve doktora tezleri üzerine yapılan araştırmalar olsa da, bibliyometrik bir analiz çalışmasının, inanç turizmi özelinde bulunmadığı saptanmıştır. Turizm pazarlamasında, inanç turizmi destinasyonlarının öneminin artması, manevi değer taşıyan mekânlara yapılan seyahatlerin, hem yerel ekonomi hem de ülke ekonomisi içinde ciddi bir gelir kalemi oluşturması ve küresel ölçekte, deniz-kum-güneş üçlemesi üzerine kurulu turizm hareketliliğinden farklı alternatif bir hizmet çeşitliliği sunması gibi nedenler, özellikle Türkiye gibi kutsal ziyaret alanlarının yoğun olarak bulunduğu ülkeler özelinde, bilimsel çalışmalar için zengin bir inceleme sahası sunmaktadır. Bu açıdan, inanç turizmi alanında günümüze dek yapılan araştırmaların profilinin, bundan sonraki araştırmalar için yol gösterici olması hedeflenmiş̧ir.

\section{Yöntem}

Bibliyometri kavramı Pritchard (1969) tarafından "matematiksel ve istatistiksel yöntemlerin kitaplara ve diğer iletişim araçlarına uygulanması" şeklinde tanımlanmıştır. Analiz odaklı yazın taramasının kullanıldığı bibliyometrik çalışmalar, sosyal bilimler alanındaki çalışmalarda sıklıkla kullanılan ve yazılı iletişimin detaylı irdelenmesine olanak sağlayan bir yöntemdir. Bibliyometrik araştırmalar, yazılı belgelerin, belirli parametreler altında analiz edilerek, bilimsel iletişime ilişkin çeşitli sonuçların elde edilmesine imkân sağlamaktadır. (Al ve Coştur, 2007: 3). Bibliyometri, bilimsel iletişime dönük çalışmalar açısından da yöntemler sunmaktadır (Borgman ve Furner, 1990: 2). 
Son yıllarda turizm alanyazınındaki çalışmalarda, bibliyometri yönteminin kullanımının artış kaydettiği gözlenmektedir. Genel turizm literatürünün yanında alternatif turizm çeşitliliğini konu alan bilimsel çalışmaların da bibliyometrik açıdan incelendiği görülmektedir. Tarım turizminden, kültür turizmine, sağlık turizminden, helal turizme kadar, turizm sisteminin farklı türlerdeki uygulama alanları üzerine yapılmış tezler, bibliyometri yöntemiyle analiz edilmiştir.

Araştırmada, nitel araştırma yöntemi (yazın taraması) kullanılmıştır. Çalışmada kullanılan parametreler; Akkaşoğlu vd. (2019: 1195) ve Demirbulat ve Dinç'in (2017:25-28) çalışmalarından faydalanılarak, tezlerin türü, hazırlandığı yıl, tezin hazırlandığı üniversite, tezin yazıldığı enstitü, tezlerin anabilim dallarına göre dağılımı, tezlerdeki danışmanların unvanları, tezlerin sayfa sayısı, tezlerin yazıldı̆̆ 1 üniversitelerin bölgelere göre dağılımı ve tezlerde kullanılan araştırma yöntemleri olarak belirlenmiştir. 1998-2019 yılları arasında Yükseköğretim Kurulu Tez Merkezinde yer alan ve başlı̆̆ında "inanç turizmi" ifadesi geçen 47 lisansüstü tezin, bibliyometri yöntemiyle incelenmesi amaçlanmıştır. Çalışmanın amacı doğrultusunda, tezlere uygulanan parametrelere yol gösteren araştırma soruları aşağıdaki gibidir.

a) İnanç turizmi başlığında hazırlanan tezlerin tür dağılımı nasıldır?

b) Tezler hangi yıllarda yazılmıştır?

c) İlgili tezlerin hazırlandığ 1 üniversiteler hangileridir?

d) İnanç turizmine yönelik hazırlanan tezlerin hazırlandığı enstitüler hangileridir?

e) Tezlerin anabilim dallarına göre dağılımı nasıldır?

f) Tezlerdeki danışmanların unvanlarına göre dağılımı ne şekildedir?

g) Tezlerin sayfa sayısı kaçtır?

h) Tezlerde kullanılan araştırma yöntemleri nelerdir?

i) İnanç turizmi başlığında hazırlanan tezlerin bölgelere göre dağılımı nasıldır?

İnanç turizmi başlığındaki tezlerin taranması, YÖK TEZ veri tabanında bulunan tarama terimi kısmına 'inanç turizmi' anahtar kelimesi girilerek ve aranacak alan kısmı 'tez adı', izin durumu 'tümü' ve tez türü 'tümü' olarak işaretlenerek gerçekleştirilmiştir. 09.12.2019 tarihinde (tez.yok.gov.tr) yapılan tarama sonucunda toplamda 47 yüksek lisans ve doktora tezine ulaşılmıştır. YÖKTEZ merkezi kayıtlarında, başlığında inanç turizmi ifadesini içeren ilk tezin 1998 yılında Gazi Üniversitesi bünyesinde yayımlandığı belirlenmiştir. Bu açıdan, inanç turizmi alanında yazılan tezlerin bibliyometrik analizlerinin doğru bir biçimde yapılabilmesi için, kronoloji ön planda tutulmuş, alan ile ilgili ilk tez ile son tezin yayımlandığı yıllar esas alınmıştır.

\section{Bulgular}

Araştırma soruları 1şığında hazırlanan parametreler yardımıyla oluşturulan istatistiki veriler, grafik ve tablolar halinde sunulmuştur.

Tablo 1: İnanç Turizmi Başlığında Yayımlanan Tezlerin Tür Dağılımı

\begin{tabular}{|c|c|c|}
\hline Tez Türü & $\boldsymbol{f}$ & \% \\
\hline Yüksek Lisans & 45 & 95,74 \\
\hline Doktora & 2 & 4,26 \\
\hline Toplam & $\mathbf{4 7}$ & $\mathbf{1 0 0}$ \\
\hline
\end{tabular}

Başlığında inanç turizmi bulunan tezlere ilişkin tür dağılımı Tablo 1'de verilmiştir. Yayımlanan tezlerin yaklaşık \%96 'sının yüksek lisans, \%4'ünün ise doktora tezi olduğu görülmüştür. Bilimsel olarak incelenebilecek konu başlıklarının yoğun olduğu inanç turizmi alanında, Türkiye'de yazılan lisansüstü tezlerin az sayıda olduğu görülmüşsür. Ayrıca bu alanda yazılan doktora tezi sayısı 2 'dir. 
Tablo 2: İnanç Turizmi Başlığında Yayımlanan Tezlerin Yıllara Göre Dağılımı

\begin{tabular}{|c|c|c|c|}
\hline YII & Yüksek Lisans & Doktora & Toplam \\
\hline 1998 & 1 & & 1 \\
\hline \multicolumn{4}{|l|}{1999} \\
\hline \multicolumn{4}{|l|}{2000} \\
\hline \multicolumn{4}{|l|}{2001} \\
\hline \multicolumn{4}{|l|}{2002} \\
\hline \multicolumn{4}{|l|}{2003} \\
\hline \multicolumn{4}{|l|}{2004} \\
\hline 2005 & 1 & & 1 \\
\hline \multicolumn{4}{|l|}{2006} \\
\hline \multicolumn{4}{|l|}{2007} \\
\hline \multicolumn{4}{|l|}{2008} \\
\hline 2009 & 2 & 1 & 3 \\
\hline 2010 & 3 & & 3 \\
\hline 2011 & 3 & & 2 \\
\hline 2012 & 2 & & 2 \\
\hline 2013 & 2 & & 2 \\
\hline 2014 & 5 & & 5 \\
\hline \multicolumn{4}{|l|}{2015} \\
\hline 2016 & 3 & & 3 \\
\hline 2017 & 7 & 1 & 8 \\
\hline 2018 & 4 & & 4 \\
\hline 2019 & 12 & & 12 \\
\hline Toplam & 45 & 2 & 47 \\
\hline
\end{tabular}

Şekil 1: İnanç Turizmi Başlığında Yayımlanan Tezlerin Yıllara Göre Dağılım Eğilimi

0

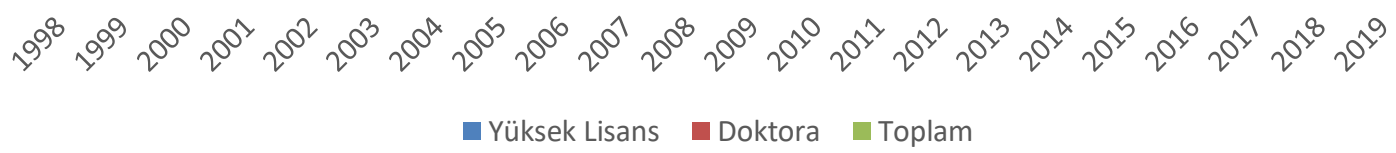

İnanç turizmi başlığında yazılan tezlerin yıllara göre dağılımı incelendiğinde, 1999-2004 yılları ile 2006-2008 yılları arası lisansüstü tezin bulunmadığı görülmüştür. Bu alandaki çalışmaların 2008 yılından itibaren ivme kazandığ 1 ve yoğunluğun yüksek lisans tezlerinde olduğu saptanmıştır. 
En fazla yüksek lisans tez çalışmasının 2019'da yayımlandığı tespit edilmiştir. Bu açıdan değerlendirildiğinde, son yıllarda, alternatif turizm alanlarına dönük seyahat artışına ve bu turizm çeşidinin küresel turizm içindeki payının artmasına, bilim dünyasının kayıtsız kalmadığı söylenebilir.

Tablo 3: İnanç Turizmi Başlığında Yayımlanan Tezlerin Üniversitelere Göre Dağılımı

\begin{tabular}{|c|c|c|c|}
\hline Üniversite & $f$ & Üniversite & $f$ \\
\hline $\begin{array}{c}\text { Dokuz Eylül } \\
\text { Üniversitesi }\end{array}$ & 5 & Batman Üniversitesi & 1 \\
\hline Marmara Üniversitesi & 2 & $\begin{array}{l}\text { Necmettin Erbakan } \\
\text { Üniversitesi }\end{array}$ & 2 \\
\hline Kastamonu Üniversitesi & 5 & Ege Üniversitesi & 1 \\
\hline Selçuk Üniversitesi & 2 & Gaziantep Üniversitesi & 1 \\
\hline $\begin{array}{l}\text { Karamanoğlu Mehmet } \\
\text { Bey Üniversitesi }\end{array}$ & 1 & $\begin{array}{c}\text { Hacı Bektaş-1 Veli } \\
\text { Üniversitesi }\end{array}$ & 1 \\
\hline Mersin Üniversitesi & 1 & Trakya Üniversitesi & 1 \\
\hline Gazi Üniversitesi & 5 & Sakarya Üniversitesi & 2 \\
\hline Kırklareli Üniversitesi & 1 & $\begin{array}{c}\text { Nuh Naci Yazgan } \\
\text { Üniversitesi }\end{array}$ & 1 \\
\hline İstanbul Üniversitesi & 4 & Karabük Üniversitesi & 1 \\
\hline $\begin{array}{c}\text { Hasan Kalyoncu } \\
\text { Üniversitesi }\end{array}$ & 1 & $\begin{array}{c}\text { Muğla Sitk1 Kocaman } \\
\text { Üniversitesi }\end{array}$ & 2 \\
\hline $\begin{array}{c}\text { Mimar Sinan } \\
\text { Üniversitesi }\end{array}$ & 1 & $\begin{array}{c}\text { Türk Hava Kurumu } \\
\text { Üniversitesi }\end{array}$ & 1 \\
\hline $\begin{array}{c}\text { Süleyman Demirel } \\
\text { Üniversitesi }\end{array}$ & 1 & Balıkesir Üniversitesi & 2 \\
\hline Kırklareli Üniversitesi & 1 & $\begin{array}{c}\text { Aydın Adnan Menderes } \\
\text { Üniversitesi }\end{array}$ & 1 \\
\hline & & Dicle Üniversitesi & 1 \\
\hline Toplam & & & 47 \\
\hline
\end{tabular}

Tablo 3 incelendiğinde, 27 farklı üniversitede alan ile ilgili tez yazıldı $\breve{g}$, en çok yayınlanan tezin Dokuz Eylül Üniversitesi, Gazi, Üniversitesi ve Kastamonu Üniversitesi'nde olduğu görülmektedir. Özellikle, Dokuz Eylül Üniversitesi ve Kastamonu Üniversitesi'nin eğitim müfredatında, inanç turizmi tezli yüksek lisans programlarının bulunmasının, bu alandaki bilimsel çalışmaların artmasına katkı sağladığı düşünülmektedir. Alanda yazılan 2 doktora tezinin Dokuz Eylül Üniversitesi ile Marmara Üniversitesinde yazıldığı belirlenmiştir. 
Tablo 4: İnanç Turizmi Başlığında Yayımlanan Tezlerin Üniversitelerin Bulunduğu Bölgelere Göre Dağ 11 ımı

\begin{tabular}{|c|c|c|}
\hline \multirow{2}{*}{ Bölgeler } & \multicolumn{2}{|c|}{ Yüksek Lisans + Doktora } \\
\cline { 2 - 3 } & $\boldsymbol{f}$ & \multirow{2}{*}{} \\
\hline Akdeniz & 2 & 4,27 \\
\hline Doğu Anadolu Bölgesi & & 23,40 \\
\hline Ege & 11 & 8,51 \\
\hline Güneydoğu Anadolu & 4 & 25,53 \\
\hline İ Anadolu & 12 & 14,89 \\
\hline Karadeniz & 7 & 23,40 \\
\hline Marmara & 11 & $\mathbf{1 0 0}$ \\
\hline Toplam & $\mathbf{4 7}$ & \\
\hline
\end{tabular}

*Alfabetik sıraya göre düzenlenmiştir.

Tezlerin, üniversitelerin bulunduğu bölgelere göre dağılımı incelendiğinde, sırasıyla İç Anadolu $(\% 25,53)$, Ege $(23,40)$ ve Marmara $(23,40)$ bölgesinde bulunan üniversitelerde yoğunlaştığ1 görülmektedir.

Tablo 5. İnanç Turizmi Başı̆̆ında Yayımlanan Tezlerin Enstitülere Göre Dağılımı

\begin{tabular}{|c|c|c|}
\hline \multirow{2}{*}{ Enstitü } & \multicolumn{2}{|c|}{ Yüksek Lisans + Doktora } \\
\cline { 2 - 3 } & $f$ & \% \\
\hline Sosyal Bilimler Enstitüsü & 43 & 91,48 \\
\hline Fen Bilimleri Enstitüsü & 1 & 2,14 \\
\hline Eğitim Bilimleri Enstitüsü & 3 & 6,38 \\
\hline Toplam & $\mathbf{4 7}$ & $\mathbf{1 0 0}$ \\
\hline
\end{tabular}

Tezlerin enstitülere göre dağılımı incelendiğinde, büyük bir kısmının üniversitelerin sosyal bilimler enstitülerinde hazırlandığ $(\% 91,48)$ görülmektedir. Üniversitelerin Fen Bilimleri Enstitülerinde 1, Eğitim Bilimleri Enstitülerinde'nde 3 tez yayımlanmıştır. Yayımlanan doktora tezlerinin tamamı Sosyal Bilimler Enstitülerinde hazırlanmıştır. 
Tablo 6: İnanç Turizmi Başlığında Yayımlanan Tezlerin Anabilim Dallarına Göre Dağılımı

\begin{tabular}{|c|c|c|}
\hline \multirow{2}{*}{ Ana Bilim Dalı } & \multicolumn{2}{|c|}{ Yüksek Lisans + Doktora } \\
\cline { 2 - 3 } & $\boldsymbol{f}$ & $\mathbf{\%}$ \\
\cline { 2 - 3 } & 24 & 51,06 \\
\hline Turizm İșletmeciliği & 1 & 2,13 \\
\hline Üretim Yönetimi ve Pazarlama & 7 & 14,89 \\
\hline İşletme & 4 & 8,51 \\
\hline Turizm İşletmeciliği ve Otelcilik & 3 & 6,38 \\
\hline Turizm İsetmeciliği Eğitimi & 2 & 4,25 \\
\hline Coğrafya & 1 & 2,13 \\
\hline Sanat Tarihi & 1 & 2,13 \\
\hline İstanbul Araştırmaları & 1 & 2,13 \\
\hline Kültürel Miras & 1 & 2,13 \\
\hline Maliye ve Ekonomi & 1 & 2,13 \\
\hline Restorasyon & 1 & 2,13 \\
\hline Felsefe ve Din Bilimleri & $\mathbf{4 7}$ & $\mathbf{1 0 0}$ \\
\hline Toplam & & \\
\hline
\end{tabular}

Tablo 6, inanç turizmi başlığıyla yazılan yüksek lisans ve doktora tezlerinin toplam 12 ana bilim dalında yazıldığını ortaya koymaktadır. Tezlerin yarıdan fazlasının Turizm İşletmeciliği Ana Bilim Dalı'nda yayımlandığ $(\% 51,06)$ ve alanla ilgili tezlerin en az sayıda olduğu ana bilim dalının 1 tezle Felsefe ve Din Bilimleri $(\% 2,13)$ olduğu tespit edilmiştir. Doktora tezleri Turizm İşletmeciliği Anabilim Dalı ve Üretim Yönetimi ve Pazarlama Anabilim Dalı'nda hazırlanmıştır. Veriler, inanç turizmi gibi manevi destinasyonların ve bu destinasyonlardaki bakış açısının yoğun olarak incelendiği bu alanla doğrudan ilişkili olan ve interdisipliner köklerin incelenmesine olanak tanıyan Felsefe ve Din Bilimleri Ana Bilim Dalı bünyesinde hazırlanan tez sayısının düşük oranda olduğunu göstermiştir.

Tablo 7: İnanç Turizmi Başlığında Yayımlanan Tezlerin Danışmanlarının Ünvanlarına Göre

\begin{tabular}{|c|c|c|}
\hline \multirow{2}{*}{ Akademik Unvan } & \multicolumn{2}{|c|}{ Yüksek Lisans + Doktora } \\
\cline { 2 - 3 } & $\boldsymbol{f}$ & $\mathbf{\%}$ \\
\hline Profesör & 19 & 40,42 \\
\hline Doçent & 10 & 21,29 \\
\hline Doktor Öğretim Üyesi & 18 & 38,29 \\
\hline Toplam & $\mathbf{4 7}$ & $\mathbf{1 0 0}$ \\
\hline
\end{tabular}

Dağılımı

Tablo 7' ye göre, yayımlanan tezlerin, \%40,42 sinin Profesör, \%38,29'unun Doktor Öğretim Üyesi, \%21,29'unun Doçent ünvanlı akademisyenlerin danışmanlığında hazırlandığı görülmüştür. İnanç turizmi başlığında yazılan lisansüstü tezlere en fazla Profesörlerin, en az Doçentlerin danışmanlık yaptığı saptanmıştır. Yayımlanan doktora tezlerinin tamamına Profesör ünvanlı akademisyenler danışman olmuştur. 
Tablo 8: İnanç Turizmi Başlığında Yayımlanan Tezlerin Sayfa Sayılarına Göre Dağılımı

\begin{tabular}{|c|c|c|c|c|}
\hline Sayfa Sayısı & Yüksek Lisans & Doktora & Toplam & \% \\
\hline $0-99$ & 6 & & 6 & 12,76 \\
\hline $100-199$ & 32 & 1 & 33 & 70,21 \\
\hline $200-299$ & 6 & 1 & 7 & 14,89 \\
\hline 300 ve üstü & 1 & & $\mathbf{4 7}$ & 2,14 \\
\hline Toplam & & & $\mathbf{1 0 0}$ \\
\hline
\end{tabular}

İnanç turizmi başlıklı tezlerin sayfa sayıları dağılımı Tablo 8'de verilmiştir. Tezlerin büyük oranda $(\% 70,21), 100-199$ sayfa aralığında yazıldığı, sadece bir tezin (yüksek lisans) 300 sayfanın üzerine çıtığı ve toplamda 6 tezin 100 sayfanın altında kaldığı saptanmıştır.

Tablo 9: İnanç Turizmi Başlığında Yayımlanan Tezlerde Kullanılan Araştırma Yöntemlerine Göre Dağ 11 im

\begin{tabular}{|c|c|c|}
\hline \multirow{2}{*}{ Araştırma Yöntemi } & \multicolumn{2}{|c|}{ Yüksek Lisans + Doktora } \\
\cline { 2 - 3 } & & $\boldsymbol{f}$ \\
\hline Nicel & 27 & 57,44 \\
\hline Nitel & 18 & 38,29 \\
\hline Karma & 2 & 4,27 \\
\hline Toplam & $\mathbf{4 7}$ & $\mathbf{1 0 0}$ \\
\hline
\end{tabular}

Tezlerin \%57,44'ünde (27 tez) nicel, 38,29’unda nitel (18 tez) , \%4,27'sindeyse (2 tez) karma (nicel+nitel) araştırma yöntemleri benimsenmiştir. Yayımlanan 2 doktora tezinin birinde nitel diğerinde ise karma araştırma yöntemi kullanılmıştır. Nicel araştırma yönteminin kullanıldığ 1 tezlerin büyük bir kısmında anket yoluyla veriler toplanmış ve analiz edilmiştir. Nitel araştırma yapılan tezlerdeyse, yüzyüze görüşme, literatür incelemesi ve içerik analizi veri toplama teknikleri yoğun olarak tercih edilmiştir.

\section{Sonuç ve Öneriler}

Çalıșma 1998-2019 yılları arasında inanç turizmi alanında yazılan lisansüstü tezleri kapsamaktadır. 21 yıllık dönem boyunca farklı üniversitelerde yazılan tezler 9 parametre doğrultusunda incelenmiş ve elde edilen veriler analiz edilmiştir. Tür, y1l, üniversite, enstitü, anabilim dalı, danışman unvanı, sayfa sayısı, kullanılan araştırma yöntemi ve tezlerin yazıldı̆̆ üniversitelerin bölgelere göre dağglılımı kullanılan parametreler olmuştur. YÖKTEZ' de 'inanç turizmi' anahtar kelimesiyle yapılan tarama sonucunda 45 yüksek lisans 2 doktora tezinin yazıldığı görülmüştür.

Bu alanda yazılan tezlerin yıllara göre dağılımına bakıldığında, 1999 ve 2004 yılları arasında inanç turizmini konu alan herhangi bir yüksek lisans çalışmasının olmadığı görülmüştür. Ayrıca, 2006-2008 yılları arasında da lisansüstü çalışmanın yapılmadığı tespit edilmiştir. Yayımlanan tezlerin 2009 yılından itibaren sayıca artış gösterdiği, 2009-2018 yılları arasında toplam 45 tezin yayımlandığı ve en fazla lisansüstü çalışmanın 2019 yılında yapıldığı saptanmıştır. Alan ile ilişkili sadece 2 doktora tezi bulunmakta olup, 2009 ve 2017 yıllarında hazırlanmıştır.

İnanç turizmiyle ilgili tezlerin hazırlandığı üniversite sayısı, 2019 yılı itibariyle Türkiye'deki toplam üniversite sayısının (203 üniversite) \%13,30’unu oluşturmaktadır. Özellikle bu alana dönük 
lisansüstü müfredatı olan üniversitelerde hazırlandığı görülen tezlerin, Türkiye'deki bölgelere göre dağılımı incelendiğinde, Doğu Anadolu Bölgesi hariç bütün bölgelerde yazıldığı; Ege, İç Anadolu ve Marmara Bölgelerinde bulunan üniversitelerde yazılan tezlerin, inanç turizmi alanında yazılan toplam tez sayısının \%72,33'ünü oluşturduğu saptanmıştır. Farklı dinlere hitap eden ibadethanelerin ve tarihi değere sahip inanç mekânlarının sıklıkla görülebildiği Doğu Anadolu Bölgesinde, inanç turizmi alanında lisansüstü bir çalışmanın görülememiş olması, bu bölge özelinde, Türkiye'nin sahip olduğu zenginliklerin bilimsel alanda yeteri kadar incelenmediğini ortaya koymuştur.

İnanç alanında yazılan 47 tezin, 43'ü, üniversitelerin sosyal bilimler ensitülerinde hazırlanmıştır. Eğitim Bilimleri ve Fen Bilimleri Enstitülerinde hazırlanan tez sayısı az sayıdadır. Turizm ve Din Bilimleri gibi farklı iki alanın, interdisipliner çalışma bütünlügü içinde incelenmesine olanak sağlayan inanç turizmiyle ilgili tezlerin, Sosyal Bilimler Enstitülerinde hazırlanmış olması doğaldır. Tezlerin \%51,6'sı Turizm İşletmeciliği Ana Bilim Dalında yazılmış olup, 14,89'u İşletme, \%8,51'i Turizm İşletmeciliği ve Otelcilik Ana Bilim Dallarında hazırlanmıştır. Çalışmaların büyük oranda $(\% 40,42)$ Profesör ünvanlı akademisyenlerin danışmanlığında yürütüldüğü görülmüştür. Lisansüstü çalışmaların \%70,21'i, 100-199 sayfa sayısına sahip olup, 100 sayfanın altında kalan tezlerin oranı \% 12,76'da kalmıştır.

$\mathrm{Bu}$ alanda yayımlanan tezlerin, potansiyel inanç turizmi destinasyonlarının ortaya çıkarılmasına katkı sağladığı düşünüldüğünde, üzerinde çalışılmamış fiziki ve manevi mekânlar üzerine yoğunlaşacak bilimsel çalışmaların aynı zamanda ülke tanıtımı üzerinde etkili olacağı beklenmelidir. Yerli ve yabancı araştırmacıların, büyük bir veri deposu özelliği taşıyan Anadolu coğrafyası'nın, disiplinerarası çalışmalar için uygun atmosferinden faydalandırılması ve bu alandaki çalışmalar için teşvik edilmesi önemli ve yerinde olacaktır. Yapılan çalışmanın iki yönden sınırlılığı bulunmaktadır. İlki turizm alanında yapılan bibliyometrik çalışmalar kapsamında inanç turizminin incelenmiş olmasıdır. Bir diğer sınırlılıksa, analizin, 9 parametre üzerinden gerçekleştirilmiş̧ olmasıdır. Bundan sonra yapılması düşünülen çalışmalar açısından değerlendirildiğinde, turizmin farkl1 alternatif türleri üzerine hazırlanmış lisansüstü tezler, makaleler ve tebliğlerin geniş bir inceleme sahası yarattığ1 düşünülmekte olup, bu alandaki diğer çalışmalarda kullanılacak parametrelerin geliştirilebilmesinin alanyazına daha fazla katkı sağlayacağı söylenebilir.

\section{Kaynakça}

Akkaşoğlu, S., Akyol, C., Ulama, Ş. ve Zengin, B. (2019). Tarım Turizmine Yönelik Hazırlanan Lisansüstü Tezlerin Bibliyometrik Analizi. Journal of Tourism and Gastronomy Studies. 7 (2), 1193-1218.

Altaş, A. (2017). Türkçe 'ye Tercüme Edilen Gastronomi Kitaplarının Bibliyometrik Analizi. Kırklareli Üniversitesi Sosyal Bilimler Dergisi. 1 (1), 103-117.

Al, U. ve Coştur, R. (2007). Türk Psikoloji Dergisi'nin bibliyometrik profili. Türk kütüphaneciliği, 21(2): 142-163

Arslan, E.ve Emeksiz, M. (2016). Konaklama İsletmelerinde Çevre Yönetimi Konusunun Bibliyometrik Profili ve Gelecek Çalışmalar İçin Öneriler. Disiplinlerarası Akademik Turizm Dergisi. 1 (1), 1-12.

Atınç, O., Güray, K. ve Sürme, M. (2018). Helal Turizm Alanının Bibliyometrik Profili. Iğdır Üniversitesi Sosyal Bilimler Dergisi. 15, 389-408.

Ayaz, N. ve Türkmen, B.M. (2018). Yöresel Yiyecekleri Konu Alan Lisansüstü Tezlerin Bibliyometrik Analizi. Gastroia: Journal of Gastronomy And Travel Research. 2 (1), 22-38. 
Aydın, B. (2017). Yükseköğretim Kurulu Tez Merkezinde (Yöktez) Yiyecek İçecek İşletmeciliği Alanında Kayıtlı Bulunan Tezlerin Bibliyometrik Analizi. Disiplinlerarası Akademik Turizm Dergisi. 2 (1), 23-38.

Aydın, B. ve Aksöz, E.O. (2019). Destinasyon Alanında Yayınlanmış Lisansüstü Tezlerin Bibliyometrik Profili. Journal of Tourism and Gastronomy Studies. 7 (1), 615-636.

Borgman, Christin L.,\& Furner, Jonathan. (2002). Scholarly Communication and Bibliometrics. In B. Cronin (E.d). Annual Review of Information Science and Technology, 36, 3-72.

Boyraz, M. ve Sandıkçı, M. (2018). Gastronomi Bildirilerinin Değerlendirilmesi: Turizm Kongreleri Örneği. 2013-2017. Journal of Tourism and Gastronomy Studies. 6 (4), 873-889.

Bozok, D., Kılıç, S.N. ve Özdemir, S.S (2017). Turizm Literatüründe Kırsal Turizmin Bibliyometrik Analizi. Uluslararası İnsan Bilimleri Dergisi. 14 (1), 187-202.

Çiçek, D. ve Kozak, N. (2012). Anatolia: Turizm Araştırmaları Dergisi'nde Yayımlanan Hakem Denetimli Makalelerin Bibliyometrik Profili. Türk Kütüphaneciliği. 26 (4), 734-756.

Çolakoğlu, Ü., Altun, H.E. ve Kıykaç, B. (2019). Türkiye'deki Medikal Turizm Tezlerinin Bibliyometrik Profili. Anatolia: Turizm Araştırmaları Dergisi. 30 (2), 135-143.

Demirbulat Güdü, Ö. Tetik Dinç, N. (2017). Sürdürülebilir Turizm Konulu Lisansüstü Tezlerin Bibliyometrik Profili. Seyahat ve Otel İşletmeciliği Dergisi. 14(2), 20-30.

Doğaner, S. (2013). Türkiye Kültür Turizmi. İstanbul: Doğu Kitabevi.

Düşmezkalender, E. (2019). Alternatif Turizme Yönelik Bibliyometrik Bir Araştırma. Selçuk Üniversitesi Sosyal Bilimler Meslek Yüksekokulu Dergisi. 22(2), 813-824.

Karagöz, D. ve Kozak, N. (2014). Anatolia Turizm Araștırmaları Dergisi 'nin Bibliyometrik Analizi: Araştırma Konuları ve Kurumlar Arası İş Birliğinin Sosyal A $\breve{g}$ Analizi ile İncelenmesi. Türk Kütüphaneciliği. 28 (1), 47-61.

Kaynak, H., Sezgin, M. (2008). İnanç Turizmi Kapsamında Dinlerde Seyahat. Selçuk Üniversitesi Sosyal Bilimler Meslek Yüksek Okulu Dergisi. 10 (1-2), 349-360.

Kozak, N. (1996). Türkiye Turizm Tezleri Bibliyografyası (1952-1995). Ankara: Anatolia Yayınc1lık.

Özel, Ç.H. ve Kozak, N. (2012). Turizm Pazarlaması Alanının Bibliyometrik Profili (2000-2010) ve Bir Atıf Analiz Çalışması. Türk Kütüphaneciliği. 26 (4), 715-733.

Pritchard, A. (1969). Statistical Bibliography or Bibliometrics? Journal of Documentation, 25: 348349.

Sökmen, C. ve Özkanlı, O. (2018). Gastronomi Turizmi Alanyazının Gelişimi: Journal of Tourism and Gastronomy Studies Dergisinde Yayımlanan Makaleler Üzerine Bir İnceleme. Journal of Tourism and Gastronomy Studies. 6 (2), 99-127.

Sünnetçioğlu, A., Yalçınkaya, P. ve Olcay, M. (2017). Turizm Alanında Yazılmış Olan Gastronomiye İlişkin Tezlerin Bibliyometrik Profili. Journal of Tourism and Gastronomi Studies. 5 (Özel Say1), 345-354.

Şahin, S. ve Acun, A. (2015). Turist Rehberliği Alanının Bibliyometrik Profili Ulusal Turizm Kongreleri Bildirileri. Balıkesir Üniversitesi Sosyal Bilimler Enstitüsü Dergisi. 18 (34), 213234.

Tayara, M. ve Özel, Ç.H. (2019). Annals of Tourism Research Dergisinde Yayımlanan Postmodern Dönemde Turizm Konulu Makaleler: Bibliyometrik Inceleme. Anatolia: Turizm Araştırmaları Dergisi. 30 (2), 100-111. 
Tayfun, A., Küçükergin, G.F, Aysen, E., Eren, A. ve Özekici, Y.K. (2016). Turizm Alanında Yazılan Lisansüstü Tezlere Yönelik Bibliyometrik Bir Analiz. Gazi Üniversitesi Turizm Fakültesi Dergisi. 1, 50-69.

Tayfun, A., Ülker, M., Gökçe, Y. Tengilimoğlu, E., Sürücü, Ç. ve Durmaz, M. (2018). Turizm Alanında Yiyecek ve İçecek ile İlgili Lisansüstü Tezlerin Bibliyometrik Analizi. Journal of Tourism and Gastronomy Studies. 6 (2), 523-547.

Temizkan, P., Çiçek, D. ve Özdemir, C. (2015). Sağllk Turizmi Konusunda Yayınlanan Makalelerin Bibliyometrik Profili. Uluslararas1 İnsan Bilimleri Dergisi. 12 (2), 394-415.

Yılmaz, G. (2017). Restoranlarda Bahşiş Ille İlgili Yayınlanan Makalelerin Bibliyometrik Analizi. Seyahat ve Otel İşletmeciliği Dergisi. 14(2), 65-79.

Yılmaz, İ., Karakuş, Y., Çamlıca, K. ve Toprak, L.S. (2017). Turizm Alanındaki Bibliyometrik Çalışmalar: Türkiye Örneği. Turan-Sam Stratejik Araştırmalar Merkezi Dergisi. 9 (36), 8388.

Zencir, E. ve Kozak, N. (2012). Sosyal Bilimler Enstitü Dergilerinde Yayımlanan Turizm Makalelerinin Bibliyometrik Profili (2000-2010). VI. Lisansüstü Turizm Öğrencileri Araştırma Kongresi, 12-15 Nisan 2012, Anatolia Turizm Araştırmaları Dergisi ve Gazi Üniversitesi, Antalya, ss.673-682.

\section{İnternet Kaynakçası}

UNWTO (2019), http://cf.cdn.unwto.org, (Erişim Tarihi: 02.12.2019) 